GENOMA HUMANO, DESAROLLO CIENTÍFICO Y SIGLO XXI: construcción de basas interprectativas biojurídcas iluminadas por la obra de Carlos María Romeo Casabona

GENOMA HUMANO, DESENVOLVIMENTO CIENTÍFICO E SÉCULO XXI: construções de bases interpretativas biojurídicas iluminadas pela obra de Carlos María Romeo Casabona

\author{
Ana Paula Myszczuk ${ }^{1}$ \\ Universidade Tecnológica Federal do Paraná (UTFPR) \\ Jussara Maria Leal de Meirelles ${ }^{2}$ \\ Pontifícia Universidade Católica do Paraná (PUC/PR)
}

\begin{abstract}
RESUMEN
El paper tiene como problema identificar, analizar y sintetizar algunas cuestiones fundamentales en las aproximaciones, distancias e interacciones entre Ciencia, genoma humano y protección jurídica. El objetivo es demostrar que las formas jurídicas clásicas no abordan las cuestiones planteadas por la ciencia en el siglo XXI y que es necesario considerar nuevas bases interpretativas, adecuadamente biojurídicas. Para llevar a cabo la tarea de construir una protección biolegal para el ser humano, la obra de Carlos María Romeo Casabona es tanto un norte como una inspiración. Como enseña, la protección jurídica de la investigación científica, los descubrimientos y las innovaciones biotecnológicas son bienvenidos, siempre que sean una herramienta que facilite el acceso de la población a los beneficios obtenidos o generados por la biotecnología y eliminen, prevengan o al menos minimicen los riesgos de daño a las personas, el medio ambiente y la materia viva en general. Basándose en esta premisa, buscase establecer bases interpretativas bioconstitucionales que puedan proyectar el desarrollo de la Ciencia como sinónimo de empoderamiento de ser humano.
\end{abstract}

Palabras clave

Bioética, Bioderecho, Bioconstitución, Manipulación Genética Humana, Desarrollo Científico.

\title{
RESUMO
}

${ }^{1}$ Graduada em Licenciatura em História (1993) e Bacharelado em Direito (1999), ambos pela Universidade Estadual de Ponta Grossa. Mestre em Direito Econômico e Social pela Pontifícia Universidade Católica do Paraná (2003). Doutora em Direito Econômico e Socioambiental pela Pontifícia Universidade Católica do Paraná (2012), com estágio doutoral na Universidade do Deusto e Universidade do Pais Basco, desenvolvendo estudos na Cátedra Interuniversitaria de Derecho y Genoma Humano (2010). Estágio posdoutoral na Universidad de Pinar del Río (Cuba), no Centro de Estudios en Medio Ambiente y Recursos Naturales (2017-2018). Estágio posdoutoral no Programa de Pós-Graduação em Bioética na Pontifícia Universidade Católica do Paraná (2016 - 2018). Professora visitante no Programa de Mestrado em Direito da Universidade de Karaganda, Cazaquistão (2011). Professora na Universidade Tecnológica Federal do Paraná (2013) - UTFPR - em cursos de graduação e no Programa de PósGraduação em Planejamento e Governança Pública (PGP) e da Universidade Aberta do Brasil - UAB (Especialização em Gestão Pública Municipal). Tem experiência na área de Direito Privado, com ênfase em Biodireito, Direito Civil e Propriedade Intelectual. Advogada em Curitiba desde 2000. Orcid: https://orcid.org/0000-0003-0232-0449

${ }^{2}$ Graduada em Direito pela Universidade Federal do Paraná, com Mestrado e Doutorado em Direito das Relações Sociais pela Universidade Federal do Paraná e Pós-Doutorado no Centro de Direito Biomédico da Universidade de Coimbra. Professora Titular de Direito Civil da Pontifícia Universidade Católica do Paraná, Professora do Programa de Pós-Graduação em Direito Econômico e Socioambiental (Mestrado e Doutorado) e do Programa de Pós-Graduação em Bioética (Mestrado), da Pontifícia Universidade Católica do Paraná. Procuradora Federal aposentada. Com ênfase no Direito Civil, atua principalmente nos seguintes temas: Biodireito e Desenvolvimento Social, Aspectos Jurídicos da Reprodução Humana Assistida, Erro Médico e Responsabilidade Civil, Dignidade do Paciente, Terapia Celular, Vida Humana Embrionária, Meio Ambiente e Saúde Mental, dentre outros. Orcid: https://orcid.org/0000-0003-3755-603X 
O artigo tem como problemática identificar, analisar e sintetizar algumas questões fundamentais nas aproximações, distanciamentos e interações entre Ciência, genoma humano e proteção jurídica. Visa demonstrar que as formas jurídicas clássicas não dão conta de solucionar os questionamentos trazidos pela Ciência no século XXI e que novas bases interpretativas, propriamente biojurídicas, precisam ser pensadas. Para realização dessa tarefa de construção de uma proteção biojurídica ao ser humano, aqui especialmente ser humano imaterial, a obra de Carlos María Romeo Casabona é tanto norte quanto inspiração. Conforme leciona, a proteção jurídica das investigações científicas, das descobertas e inovações biotecnológicas são benvindas, desde que sejam uma ferramenta que facilite o acesso da população aos benefícios obtidos ou gerados pela biotecnociência e eliminem, previnam ou ao menos minimizem os riscos de danos para o ser humano, o meio ambiente e a matéria viva em geral. Pautando-se nessa premissa é que se buscou estabelecer bases interpretativas bioconstitucionais que possam projetar o desenvolvimento da Ciência enquanto sinônimo de empoderamento do ser humano.

PALAVRAS-CHAVES

Bioética, Biodireito, Bioconstituição, Manipulação Genética Humana, Desenvolvimento científico.

\section{CONSIDERACIONES INICIALES}

El desarrollo de la Ciencia en el siglo XX dio lugar a muchos avances técnicos y preguntas bioéticas variadas. La misma civilización que se prepara para colonizar otros planetas convive con males aparentemente insolubles como el hambre, la miseria y la devastación del medio ambiente. Además, hoy en día, viviese las agruras de la pandemia del Covid-19³ . La posibilidad de aplicarse conocimientos técnicos alteró irreversiblemente el ser humano, el medio ambiente y se profundizó la contradicción interna en la Ciencia.

Cuestionados, los conceptos clásicos de la Ciencia moderna están puestos a prueba. Nuevos entendimientos sobre lo que es y cuál es la función del conocimiento científico son buscados y los movimientos que defienden una mas gran sinergia entre Ciencia, genoma humano y protección jurídica ganan fuerza. La sociedad y los científicos se despiertan a una reflexión sobre en qué camino quiere irse la humanidad y qué mundo quiere dejar para las generaciones futuras.

Esas discusiones llegan a los fundamentos hermenéuticos del sistema jurídico clásico y permiten el desarrollo de nuevos paradigmas interpretativos sobre los institutos jurídicos. Para llevarse a cabo la tarea de construirse una protección biojurídica para los seres humanos, la obra de Carlos María Romeo Casabona es tanto el norte como una inspiración.

Antes de tratar cuestiones científicas, es imperativo informar sobre la aproximación de las autoras con la obra y con la persona humanista que es el profesor Romeo Casabona. Inicialmente, en el Seminario Internacional sobre Bioderecho, el 29 de mayo de 2002, celebrado en la Pontificia Universidad Católica de Minas Gerais - PUC/Minas, por invitación de la profesora Maria de Fátima Freire de Sá, la profesora Jussara Maria Leal de Meirelles dio una

${ }^{3}$ El nombre ha sido utilizado oficialmente por la Organización Mundial de la Salud (OMS) desde principios de febrero de 2020. COVID significa Enfermedad de COrona VIrus (Enfermedad del Coronavirus). 
conferencia sobre la "Situación jurídica del embrión humano", resultado de su investigación doctoral, en la cual, desde 1997, había buscado las enseñanzas del profesor Romeo Casabona. En ese seminario, la profesora Jussara pudio conocerlo personalmente.

En otra oportunidad, ya en 2008, por invitación de la Profesora Jussara Meirelles, entonces coordinadora del proyecto de investigación financiado por el CNPq y titulado "Terapia celular humana: límites y posibilidades de un orden ético y legal" (2005-2008), el profesor Romeo Casabona participó en un congreso sobre la materia (Semana Internacional de Investigación en Derecho y Desarrollo Tecnológico: de la sociedad globalizada a los desafíos de la Biomedicina), realizado en el Programa de Posgrado en Derecho de la Pontificia Universidad Católica de Paraná - PUCPR. En ese evento, participaron, también, la profesora Maria de Fátima Freire de Sá y la profesora Ana Paula Mysczuk, entonces estudiante de doctorado del Programa, bajo la coordinación de la profesora Jussara Meirelles.

A partir de ahí se estableció una fructífera cooperación científica entre el PPGD de PUC/PR, el PPGD de PUC/Minas y la Cátedra de Derecho y Genoma Humano, coordinada por el Prof. Romeo Casabona, en la Universidad del País Basco/Bilbao/España. Fue en esa Cátedra que la profesora Ana Paula Myszczuk realizó una estancia doctoral. entre 2009 y 2010. En la oportunidad, participó de numerosos congresos, seminarios y proyectos, bajo la dirección del prof. Romeo Casabona y tuvo la suerte de verlo conformar su junta de doctorado, en 2012.

Después de eso, las autoras escribieron varios artículos para la Revista de Derecho y Genoma Humano, que es publicada por la Cátedra. También estuvieron presentes en la conmemoración del 20 aniversario de la Cátedra de Derecho y Genoma Humano, en 2014, presentaron dos artículos. La profesora Ana Paula Myszczuk, regresó a la Cátedra para una corta estancia, en 2018, iniciando una colaboración, también, con el Programa de Posgrado en Planificación y Gobernanza Pública, Universidad Tecnológica Federal de Paraná (UTFPR), donde es catedrática.

En las casi dos docenas de artículos/capítulos/revisiones que las autoras escribieron juntos, refleja muy fuertemente el pensamiento visionario y humanista de Carlos María Romeo Casabona. Especialmente, la obra, "El Derecho y la Bioetica ante los límites de la vida humana” (ROMEOCASABONA, 1994), representa para ellas un hito en la formación de conceptos y fundamentos para las reflexiones que propusieron sobre nuevas bases interpretativas para el Bioderecho. Tres de los entendimientos de la obra de Romeo Casabona son básicos para ellas y para el presente paper.

Primer, el desarrollo de las Ciencias Biomédicas llevó a que las decisiones de los profesionales de salud fuesen cada vez más complejos e involucraran no sólo a los pacientes, 
sino a todo el cuerpo social. Las implicaciones científicas de ciertos procedimientos ya no se limitan únicamente a las relaciones médicos/pacientes, ya que su aplicación pone en juego no sólo los intereses privados de la persona afectada, sino todos los seres humanos como especie (ROMEO CASABONA, 1994).

Según, es obligación de las generaciones actuales tener un instrumento de valor ético y jurídico para hacer frente a las nuevas realidades, incluso antes de que surjan y se sienten irreversiblemente en la sociedad. El discurso jurídico debe ser provisional, inevitablemente abierto y objeto de revisión. Déjese que las generaciones futuras decidan lo que les convenga, según sus propias valoraciones (ROMEO CASABONA 1994).

Tercer, se acoge con satisfacción la protección jurídica de la investigación científica, los descubrimientos y las innovaciones biotecnológicas, siempre que formen parte de una herramienta que facilite el acceso de la población a los beneficios obtenidos o generados por la Biotecnología y eliminen, prevengan o al menos minimicen los riesgos de daño a las personas, el medio ambiente y la materia viva en general (CASA ROMEOBONA, 2017).

Sobre la base de esas premisas y con un profundo respeto por el pensamiento de Romeo Casabona, el paper presenta algunas lagunas que las técnicas de manipulación del genoma humano generaron a la protección jurídica en el sistema jurídico-civil clásico. Analiza algunas cuestiones fundamentales en las aproximaciones, distanciamientos e interacciones entre Ciencia, genoma humano y protección biojurídica. Busca hacer acercamientos al pensamiento de Romeo Casabona, con el objetivo de establecer bases interpretativas bioconstitucionales que puedan proyectar el desarrollo de la Ciencia como sinónimo de empoderamiento del ser humano.

\section{ENFOQUES ENTRE CIENCIA, ÉTICA Y EL SIGLO XXI}

Al largo de la historia, Ciencia y Ética tuvieron sus periodos de aislamiento y de aproximación. Específicamente para el tema del paper, importa que, en la civilización occidental y desde el periodo Moderno, la sociedad pasó por un proceso de logocentrismo. Fue establecida la Ciencia cómo el centro del universo y una completa separación de los otros tipos de conocimientos, entre los cuales los de la Ética, se produzco (HERRERO, 1999).

Así, la construcción teórico-científica se dio desde la premisa de que todo en el universo se compone de un sistema lleno de engranajes y mecanismos de funcionamiento específicos. En esa concepción, tantos los astros, como los seres vivos están sometidos a las mismas leyes mecánicas y existirían dos mundos nítidamente separados: el natural y el artificial. Al mismo 
tiempo, de un lado estaría el ser humano, componente de ese mundo natural y, del otro, las cosas hechas por el ser humano, los miembros de ese mundo artificial (MYSZCZUK, MEIRELLES, 2017).

A eso se siguió un proceso de instrumentalización e ideologización de la razón, lo que resultó en la construcción del llamado “paradigma mecanicista”, en la visión antropocéntrica del mundo y en la generación de un discurso de dominación de la Naturaleza, por medio del control y previsión de sus fenómenos.

Esa construcción fue posibilitada por la “abstracción” de la Naturaleza, aprendiéndose apena su aspecto cuantificable y universal, olvidándose de su concretad, singularidad y cualidad. El mismo ocurrió con el ser humano, que se tornó un "sujeto” e fue destituido de su memoria, cultura, historia y pasión (CARDOSO, 1998).

Fue criada una dualidad entre el sujeto y el objeto, de manera que el primer pudiese manipular, apropiar, analizar, destruir, reconstituir y/o trasformar lo según, de acuerdo con sus planos y cálculos. Así la Ciencia se integró en la sociedad y actividades que operan la trasformación del mundo, aparte de conectar los avances teóricos-científicos con campos cada vez más vastos, incluidos ahí, los propios seres humanos (HERRERO, 1999).

Por otro lado, la instrumentalización de la razón forjó la separación entre Ciencia y Filosofía y la, consecuente, fragmentación del conocimiento. Fueron criadas especialidades disciplinares cada vez más compartimentadas e islas epistemológicas, dogmáticas y acríticamente enseñadas se formaron (BORBA, 2010). Cómo resultado, la Ciencia pasa a ser una “commodity” extremamente comercializable.

La misma separación ocurrió entre Ciencia y Ética. La razón instrumental organizó y adecuó los fines a los medios, sen espacio para reflexiones en términos de valores, sino en términos de eficiencia. Eso produzco una contradicción: mientras los fundamentos de la Ciencia pusieron el ser humano en posición de sujeto activo, el cual dominaba la Naturaleza, de otro, el mismo saber, utilizado como un instrumento de poder, en lo mas de las veces, acabo por destruir las condiciones del ser humano realizarse como sujeto (CARDOSO, 1988).

Sobrevino, también, una división en el ser humano. De un lado estaba su mente, casi siempre confundida con su alma. De otro su cuerpo, que pude ser explicado, analizado y comparado a una maquina hidráulica o a un reloj. Cuerpo y mente son independientes. En el cuerpo reside la materialidad y finitud humana, ya que en su mente residiría la “esencia” del ser humano (MYSZCZUK, MEIRELLES, 2017).

En el inicio del siglo XX, el estereotipo del investigador, construido como aquél ser racional que recurre a procedimientos lógicos para averiguar solamente la "verdad de las cosas” 
y de la representación de la Ciencia como un conocimiento de leyes objetivas de la naturaleza pasó a ser duramente cuestionada por la Filosofía de la Ciencia (GONÇALVES, 1991).

Eses cuestionamientos destacan la existencia de variados entrabes políticos y éticos en la sociedad. Entrabes éticos por que la repercusión de las descubiertas y usos del conocimiento científico sobre las relaciones humanas colocan la humanidad en una encrucijada donde:

a) o la lógica de la racionalidad técnica se torna el único principio regulador y orientador de la expansión sin límites a su poder, o;

b) la sociedad hace un gran esfuerzo en el sentido de inserir la variable ética en las cuestiones científicas y de ajustar la racionalidad técnica a los ideales humanitarios construidos al largo de los siglos (HERRERO, 1999).

Esas limitaciones fueron aumentadas a partir de la segunda mitad del siglo XX, cuando las ambigüedades de los procesos científicos-tecnológicos pasaron del plan teórico al existencial. Fue posible verificarse, en la vida cotidiana, tanto la deterioración del medio ambiente físico y social, cuanto de posibilidades inimaginables de un mundo altamente tecnológico.

En ese contexto, dos trasformaciones hicieron con que la visión mecánica de la Ciencia, del ser humano y de la Naturaleza fuesen siendo sustituidas por una perspectiva moleculardigital. La primera es la transición para una sociedad posindustrial o informacional. La segunda es la trasformación en la forma de organización social, en que la generación, el procesamiento y la trasmisión de datos informacionales conviértanse en fuentes fundamentales de productividad y de poder (MYSZCZUK, MEIRELLES, 2017).

Además, pasase a comprender la Naturaleza de forma representativa, una información, así como la materia viva como una virtualidad. Remodelase la basa material de la sociedad a el lenguaje de la información, centrándose en la decodificación, manipulación y reprogramación de códigos. En esa nueva realidad la principal materia-prima es la vida, que pasa a ser analizada apena como un código, $n$ dígito que puede ser trasmitido e informar circuitos o fibras ópticas. En resumen, tense el pasaje del concepto de ser humano máquina al de ser humano información (MYSZCZUK, MEIRELLES, 2017).

Igualmente, en la actualidad, el capital se ha atrincherado profundamente en la vida y los genes humanos, trasformando el genoma en una fuente inagotable de capital, valor y riqueza. El genoma se ha convertido en “el” biocapital por excelencia. Cada ser humano es una fuente autónoma de biocapital y el genoma humano el más gran patrimonio de la humanidad y de la persona, su patrimonio esencial. 
Se buscan inúmeras formas de aproximación al biocapital humano con fines comerciales, sea para garantizar la ganancia de beneficios materiales. Pero, no se puede basar el análisis apena en parámetros económicos, pues límites jurídicos/humanísticos deben ser aplicados en esa aproximación. Sin ningún límite/norte jurídico, se podría crear la figura del “ser humano-fuente”: aquél desconsiderado en sus características humanas y considerado por las ventajas que su biocapital individual puede bioprospectar. Eso crearía nuevas formas de discriminación y, posiblemente, la trasformación del ser humano en bien de consumo.

El ser humano no puede ser reducido a sus caracteres genéticos, ya que el genoma se expresa en consonancia con el ambiente natural y social de cada individuo, su estado de salud, sus condiciones de vida, nutrición y educación. El determinismo o reduccionismo genético puede llevar a la distinción entre los individuos y grupos sociales con basa exclusiva en sus características genéticas. Al mismo tiempo en que se garantiza el derecho a la investigación científica y a los ganes económicos, es impuesta la responsabilidad de cuidado, cautela, integridad y honestidad intelectual en la aproximación comercial y en las actividades decurrentes de esa aproximación.

Así que exigiese una excelencia en actuar, o sea, una actitud ética. El cuidado significa una evaluación previa de los potenciales riesgos y beneficios para el investigador, la industria y las personas, así como de los requisitos y exigencias legales para actuación y utilización de la información genética humana. La cautela determina la obligatoriedad de sopesarse los riesgos y beneficios que se puede obtener a partir de determinado procedimiento con fines comerciales. La honestidad intelectual designa un deber de informar al sujeto de las consecuencias del procedimiento. La integridad determina que el investigador asuma todos los riesgos advenidos de sus actividades de bioprospección, independiente de cualquier circunstancia y delante de todos los daños que puedan ser causados al sujeto o paciente (MYSZCZUK, MEIRELLES, 2014).

Esta situación ha llevado a la sociedad a cuestionarse si el avance técnico sin progreso moral humano es válido. El establecimiento de una relación entre la Ética y la Ciencia se ha convertido en el mas gran desafío para la base crítica del conocimiento y de las prácticas científicas actuales (CARDOSO, 1998).

\subsection{Límites bioéticos y desarrollo de la Ciencia}


Hay que recordarse que es el propio desarrollo obtenido por la Ciencia Moderna el punto de partida para las cuestiones éticas de hoy. Aunque la Ciencia se ha desarrollado lo suficiente para formular sus propios principios y métodos, no está libre del control interno y externo.

El control científico interno es establecido por los propios investigadores y la comunidad científica, basado en criterios que incluyen: control estricto de la metodología utilizada, honestidad en la presentación de resultados de la investigación a los pares y beneficios para la vida, especialmente humana.

Por otro lado, el control externo, mucho más amplio, es llevado a cabo por la sociedad organizada y se refiere a la aplicación de ese conocimiento en el mundo real. Pero ¿cómo se establecen estos criterios? La Ética es compuesta de dos juicios: sapiencial y circunstancial.

El juicio de la sabiduría acepta el valor universal del bien. El circunstancial considera la coyuntura temporal, espacial e histórica. Igualmente, la Ética está siempre actualizada y puede con vivir con cualquier avance científico, pudiendo formular un juicio ético relevante que respete la libertad de investigación, ya que se formó a la vista de una determinada realidad y tiempo (PEGORARO, 2010).

Teniendo en cuenta estos principios, los desafíos planteados a la Ciencia por la Biotecnología del siglo XXI son, en cierto modo, muy diferentes. Así que, tal vez, la opción más apropiada es la adopción, no de criterios éticos, sino criterios Bioéticos para el control externo de la investigación científica.

La Bioética surgió en esta nueva coyuntura cultural y se presenta como una de las formas de alcanzar la responsabilidad de la razón. Puede convertirse en un faro ético para guiar las relaciones humanas con todas las áreas del conocimiento, ya que añade a los criterios sapientes y circunstanciales un análisis transdisciplinar, complejo y plural (BORBA, 2010).

Es transdisciplinar porque analiza el complejo problema de la vida a través de una pluralidad de perspectivas que incluyen la vida y las Ciencias Sociales, además de la Filosofía y otras inauditas e impensables sin la sinergia transdisciplinaria. Con eso, construye un conocimiento que trasciende la posibilidad de los campos tradicionales (FERRER, 2009).

No reduce el conocimiento a la Ciencia o la Filosofía, sirve como puente para la construcción de pensamientos complejos y admite concepciones complementarias y antagónicas (BORBA, 2010). Es parte de múltiples razones y sus relativismos, concibiendo que el pensamiento analítico y dialéctico no son excluyentes. Es pluralista, adoptando un deber de respeto al ser humano hacia otro y de todos con la humanidad, asumiendo una actitud integral hacia el otro, la sociedad y la naturaleza (GOLDIN, 2006). 
Romeo Casabona (1994) considera que la incorporación de criterios de Bioética en los estudios jurídicos debe ser impulsada. Puede proveer la orientación para alcanzar un acuerdo social sobre los retos planteados por la Biotecnología y actuar como una fuente importante en la reelaboración jurídica o la producción normativa. Recuérdese que la elaboración de la mayoría de los instrumentos jurídicos internacionales relacionados a la Biotecnología es el resultado de la aplicación de la metodología de la Bioética, multidisciplinar y pluralista, y no de la lógica del sistema jurídico clásico (ROMEO CASABONA, 2017).

Sin embargo, por mucho que se pueda adoptar la Bioética para el análisis de criterios externos e incluso internos para dar validez a lo que se puede considerar apropiado para la Ciencia, en determinado sitio y momento histórico, es sólo un camino entre varios otros que se puede tomar. No se convierte en obligatorio y puede ser simplemente ignorado por la Ciencia y el Mercado (PEGORARO, 2010).

Por todo, al criterio de sabiduría y circunstancial, debe incluirse un tercero: el de las leyes sociopolíticas. Ese criterio aporta objetividad a los límites internos y externos de la investigación científica, siendo el momento de la plenitud del juicio ético (PEGORARO, 2010). Las normas jurídicas, obligatorias y coercitivas, deben actuar de manera a evitar que los científicos sucumban a la tentación experimental y a la presión de los intereses económicos (LOUREIRO, 2009).

\section{CIENCIA, DERECHO Y BIODERECHO}

Es en la externalización de la Ciencia es que se encuentra la explicación y legitimación de la interferencia de la ley. La investigación es bastante libre cuando se guía por sus principios internos; pero la aplicación de los resultados, productos o procedimientos obtenidos depende de la legislación sociopolítica.

Eso se debe al cambio en los propios fundamentos de la Ciencia. En el modelo tradicional, los intereses científicos involucrados en la investigación no parecen presentarse como absolutamente contradictorios o en conflicto directo con la sociedad. Sin embargo, la investigación básica comenzó a utilizar técnicas e instrumentos que podrían interferir incisivamente en la realidad física y social, lo que creó relaciones más extensas e intensas entre la sociedad y la Ciencia y entre la Ciencia y la Economía.

Este proceso modificó la valoración y la estructura normativa de la Ciencia, que se convirtió en algo comercialmente útil. Así, una Ética exclusivamente interna al conocimiento resulta insuficiente y debe complementarse con el ordenamiento jurídico. La ley debe 
garantizar, por una parte, que se definan las normas de conducta que intervienen directamente en el rendimiento del investigador y pueden prevenir cualquier acto perjudicial. Por otra parte, la libertad de la comunidad científica de comportarse de conformidad con la normativa establecida en materia de control interno (GONÇALVES, 1991).

Romeo Casabona (1994) señala que el Derecho, igual que la Ética, se desarrolla en el mundo de la axiología y de los valores. Sin embargo, forma parte de esto tanto en su carácter coercitivo, como en la forma de manifestarse, a través de la legislación, que se legitima cuando se ha forjada en un Estado plural y democrático. Así, el problema jurídico consiste en detectar los nuevos valores éticos y sociales necesarios para asimilar o afrontar las nuevas realidades sociales, analizar cómo se crean estos valores y también entender cómo se integran con la ley.

Todo se resolvería si las leyes sociopolíticas, por desgracia, no presentara una seria contradicción: el sistema jurídico brasileño se basa en el derecho escrito. Por lo tanto, a medida que la ley se congela en el tiempo, la costumbre crece y se diversifica. Por lo tanto, es necesario encontrar soluciones para que la ley se renueve y se adapte a la Bioética de hoy (PEGORARO, 1998). Y ahí es donde surge otro gran problema para el Derecho.

La construcción de la forma actual de protección jurídica se originó en los siglos XVII y XVIII, sobre la base del paradigma mecanicista y como consecuencia del Estado moderno. En este contexto, casi siempre, se editaron las reglas con el único propósito de satisfacer los intereses de los titulares de capital. La legalidad y la seguridad jurídica fueron los principales instrumentos utilizados para garantizar el poder y la dominación, creando un discurso ideológico, donde el Estado se presentó como el gran racionalizador/garante de la sociedad (OLIVEIRA, 2008).

Sobre la base de una racionalidad puramente económica, esta nueva forma de organización social se basaba en la propiedad privada, que comenzó a ocupar el centro gravitacional del orden social. Así, el sistema jurídico-civil clásico estaba compuesto por una serie de elementos esenciales, sin los cuales la protección del ser humano no podría ser efectivada, que son: titulares de derechos, objetos de derechos y relaciones jurídicas. (MYSZCZUK, MEIRELLES, 2017).

Ese sistema redujo al ser humano en un "sujeto" y lo convirtió en titular de una capacidad general y abstracta para ser "titular de derechos y obligaciones patrimoniales". El tema se activa de ciertas categorías (persona, nasciturus y prole eventual), formando parte de ciertas relaciones jurídicas, que le otorgan cierta propiedad sobre los objetos (MYSZCZUK, MEIRELLES, 2014). Si las categorías no se activan y no se crea ninguna relación jurídica, la protección jurídica no se efectiva. 
Además, el Derecho es una categoría producida para la realización de derechos de propiedad y no derechos personales. Las relaciones jurídicas disciplinadas por las normas contenidas en las codificaciones civiles clásicas se constituyen entre los intereses de propiedad involucrados y no exactamente entre los seres humanos. Los derechos existenciales inherentes a la persona, como la vida, la libertad, el honor, etc., permanecen fuera de la racionalidad del sistema o se adaptan a esta realidad (MYSZCZUK, MEIRELLES, 2017).

Staffen y Zambam (2015), reflexionando sobre la sociedad globalizada contemporánea y la revolución tecnológica, destacan que la desterritorialización del Estado, la defensa de las estructuras tradicionales y el constitucionalismo requieren cambios y transformaciones en espacios jurídicos, políticos, económicos y culturales. Un análisis basado en la perspectiva exclusiva de la protección de quien posee un derecho categorizado no resuelve los conflictos relacionados con las implicaciones de la biotecnología para el ser humano.

Sigue siendo evidente, en la segunda década del siglo XXI, el paso en falso entre la actual protección jurídica clásica, basada en el paradigma mecánico-electrónico y en el ser humano-máquina, del desarrollo científico, basado en el paradigma molecular-digital y el ser humano-información. Se pueden traer varios ejemplos a este análisis:

a) la cuestión de los embriones in vitro, que reveló la distancia entre la persona establecida por el derecho formal y la palpitante vida humana en el laboratorio. El avance científico de los métodos artificiales de reproducción humana permitió la concepción extrauterina y la existencia de embriones in vitro, una nueva realidad, totalmente alejada de la tradición que fundaba las codificaciones.

La protección de los embriones no encontró respuestas en la categorización/sistematización derivada del Derecho Civil clásico, ya que ese vinculaba la protección jurídica a la perfecta adecuación a las figuras jurídicas de la persona, nasciturus o prole eventual. Se pregunta al Derecho Civil clásico: ¿qué es el embrión?

En este sistema basado en la estructura formal de la relación jurídica, las personas son consideradas súbditas, no porque reconozca su naturaleza humana y dignidad, sino porque son adecuadas a lo que el Derecho les asigna como poderes u obligaciones, delimitando el ejercicio de poderes o exigiendo el cumplimiento de los deberes (MEIRELLES, 1990).

b) Otro ejemplo es lo que ha estado ocurriendo con la noción clásica de subjetividad jurídica. La subjetividad, que se traduce en propiedad de los derechos, ha sido aprehendida en un sentido cada vez más amplio, superando los límites inicialmente establecidos y extendiéndose más allá del tema categorizado. 
c) Aún, las técnicas científicas actuales son capaces de traducir al ser humano en datos genéticos, en una cadena química que puede ser descifrada, separada y pulverizada en diversos campos y para diferentes propósitos. Eso hace que ya no sea tan simple pensar en un cuerpo sano e indiviso, del cual el ser humano es el poseedor. Uno se pregunta: ¿cómo proteger al ser humano en una realidad donde el cuerpo se ha vuelto obsoleto y lo que importa es la información, algo abstracto, sin las ataduras de la materialidad y distante de la propiedad?

d) Otra cuestión importante es el uso de pruebas genéticas para la contratación de trabajo. Qué hacer cuando el cuerpo humano se vuelve prescindible y lo que importa es sólo una cierta información. ¿Cómo proteger al ser humano de convertirse en un "enfermo sano", en vista de lo que dicen sus genes sobre él /ella?

e) Y una de las preguntas más inquietantes: ¿cómo aplicar el principio de dignidad humana, cuando ya no existe el cuerpo humano y sólo una virtualidad codificada para la protección?

Todos esos puntos, esas laconas en la protección jurídica, obligan a los juristas a concluir que, en el análisis de cuestiones relacionadas con la Biotecnología, es esencial reinterpretar varias de las normas jurídicas con bases nuevas y renovadas. Es necesario revisar las categorías y conceptos tradicionalmente utilizados y formulados para situaciones de propiedad (MYSZCZUK, MEIRELLES, 2017).

No basta simplemente con extender la noción de sujeto de derecho dictada por el sistema clásico a nuevas realidades. Los nuevos derechos, los nuevos actores sociales y las nuevas demandas exigen otras formas de ecuación y protección de los activos legalmente relevantes y de carácter universal. Pero ¿qué camino se puede tomar para actualizar eficientemente el sistema jurídico para abordar los problemas del siglo XXI? En la respuesta a este problema está que la ley encuentra el camino de la Bioética y el Bioderecho ${ }^{4}$.

Mucho se ha dicho sobre la necesidad de la formulación de una nueva disciplina, rama o termología para abordar las cuestiones entre el Derecho y la Bioética. Para muchos juristas, el Derecho, dentro de sus propias formas actuales, podría resolver los problemas relacionados con el desarrollo de la Ciencia, sin tener que sacar a la luz una nueva forma epistemológica. Es decir, el propio sistema jurídico sería capaz de abordar las cuestiones bioéticas satisfactoriamente.

\footnotetext{
${ }^{4}$ En este sentido, cabe señalar que, en la lucha contra la pandemia COVID-19, se han llevado a cabo prácticas de vigilancia en varios países, con el fin de identificar y aislar a las personas infectadas con el nuevo virus. Por lo tanto, cuestiones como la intimidad, la privacidad, el secreto, la imagen, el honor y la no discriminación han sido especialmente llevadas al debate sobre su debida transparencia e inviolabilidad. Alemania, Austria, Bélgica, Brasil, Corea del Sur, Irán, Israel, Italia, Polonia y Taiwán utilizan o han utilizado tales prácticas, a mayor o menor escala.
} 
Sin embargo, así como la Ética ha avanzado y permitido el desarrollo de la Bioética, el Derecho debe avanzar y producir una nueva forma epistemológica para el análisis de cuestiones relacionadas con la Ciencia. Los problemas que se enfrentan en el siglo XXI no pueden resolverse sólo con los cimientos creados en los siglos XVII y XVIII.

No es más suficiente que el ser humano integre el sistema jurídico sólo como "sujeto de derechos”, porque a menudo esta titularización no permite su protección jurídica efectiva. Debe ser considerado en su totalidad. Por lo tanto, ya no es aceptable simplemente unir el Derecho, la Bioética y la Ciencia sin que las bases epistemológicas estén sincronizadas. Es inevitable establecer nuevas bases interpretativas, conceptos y compromisos con la vida humana (MYSZCZUK, MEIRELLES, 2014).

Por las mismas razones, en esta encrucijada, el Bioderecho es capaz de construir una forma adecuada de interpretación para que la sociedad pueda optar por reinsertar la variable ética en cuestiones científicas y ajustar la racionalidad técnica a los ideales humanitarios construidos a lo largo de los siglos.

\section{BIODERECHO: BASAS INTERPRETATIVAS EN CONSTRUCCIÓN}

El Bioderecho surge en la transición paradigmática de hoy, donde el modelo mecanicista ya no sirve para explicar las relaciones entre la Ciencia, la Ética y el Derecho, pero todavía no hay un nuevo estándar completamente retratado para guiar las acciones en el siglo XXI (BORBA, 2010).

Comparte muchas características con la Bioética, pero no se confunde con esta. Como sistemas autopoyéticos, las dos ramas utilizan el conocimiento de otras ciencias, pero mantienen su esencia. Producen y reproducen conocimientos desde la interdisciplinariedad y apuntan a la protección del ser humano integrado en el medio ambiente (LIEDKE, 2009).

Aunque la construcción de esta nueva forma de interpretación todavía esté en curso, ya es posible establecer ciertas características que determinan cómo el Bioderecho actualiza la forma de análisis de los institutos jurídicos. Reinsertando el aspecto ético y considerando al ser humano de manera integral, se basa en la racionalidad pluralista y dialogante, en la interdisciplinariedad y en el pluralismo democrático.

Esta racionalidad busca rescatar la validez formal y material del Derecho, rompiendo con la plena identificación a la ley y promoviendo valores como la dignidad de la persona humana (CAMBI, 2007). Deja de aplicar sólo la racionalidad del "sujeto", "titular" de una 
relación patrimonial jurídica, con el fin de llevar a cabo la protección del ser humano, en sus más variadas facetas, lo que exige también dar cuenta de las relaciones jurídicas existenciales.

La interdisciplinariedad ayuda al Bioderecho superar el enfoque dogmático-positivista, monológico y paralizante del sistema civil clásico, a que se adopte un enfoque integral que cruce las disciplinas tradicionales, haciéndolas dialogar con nuevas cuestiones, entre las cuales se encuentran las cuestiones bioéticas. Su objetivo es garantizar un diálogo interdisciplinario, plural y tolerante (BORBA, 2010).

Tiene, también, la tarea de salvaguardar el pluralismo democrático, mediante el suministro de condiciones procesales, el uso de un método dialogante e interdisciplinario y la normalización no positivista (BORBA, 2010). Busca constituir una perfecta sincronía entre "estar con el deber de ser y el poder de hacer", combinando el bien y el mal, con los justos y los injustos (OLIVEIRA, 2008).

Delante de esos temas, Romeo Casabona (1994) escribe que el discurso jurídico actual en torno a las Ciencias Biomédicas se ha convertido en una tarea muy difícil y compleja, requiriendo una prudencia extraordinaria tanto en cómo se quiere regular, como en lo que se pretende permitir o prohibir. Por lo tanto, deben adaptar los conceptos jurídicos al nuevo hecho, porque el Bioderecho es hecho, valor y norma y esa tridimensionalidad debe aplicarse eficazmente, de acuerdo con el momento social vivido y basado en el principio de dignidad humana (LOUREIRO, 2009).

En el camino de su construcción y como resultado de la maduración del propio Bioderecho, se buscan bases interpretativas adecuadamente biolegales para la aplicación y resolución de conflictos entre la Ciencia, la Ética y la sociedad. En esta búsqueda, el Bioderecho tiene que enfrentar y superar un sistema legal basado en la construcción mecanicista y compartimentada.

El principal fundamento que se encuentra en este escenario proviene del principio de la jerarquía de las leyes escritas, que determina que la interpretación de las normas jurídicas debe hacerse de conformidad con la Constitución Federal. Fue esta premisa tradicional la que dio origen a la innovadora concepción teórica de "Bioconstitución" o "Bioderecho Constitucional".

\subsection{Bioderecho e Interpretación bioconstitucional}

Para Baracho (2009), el concepto moderno de la Ciencia del Derecho Constitucional ha provocado varias reflexiones que buscaban una nueva concepción de la Constitución, adaptada a las grandes transformaciones del mundo contemporáneo causadas por el problema de la 
Bioética, el Bioderecho y el desarrollo científico. De esta manera, el concepto de Bioconstitución puede traer una oxigenación en la forma de interpretación de las reglas constitucionales brasileñas, recurriendo a la defensa del ser humano y del medio ambiente. Por lo tanto, es ineludible establecer puntos de referencia interpretativos que guíen una interpretación biocontextualizada.

El Bioderecho Constitucional se caracteriza por ser un conjunto de principios y normas, formal o materialmente constitucionales, que se ocupan de las acciones u omisiones del Estado o entidad privada en sus relaciones con la Biotecnología. Se basa en la protección de la vida, la identidad, la integridad y la salud de los seres humanos actuales y futuros (BARACHO, 2009). Esta forma de interpretación parte del principal valor y base común para analizar los conflictos entre la ciencia y la sociedad, sea en Brasil o en otras partes del mundo: el respeto a la dignidad humana.

En este contexto, la Constitución Federal brasileña de 1988, por sí misma, ya ha representado una innovación hermenéutica: fue la primera Carta en la historia del constitucionalismo brasileño que se reservó un capítulo exclusivo para establecer los principios bajo los cuales se funda el Estado brasileño. Entre estos principios esenciales, la dignidad de la persona humana es elegida cómo el fundamento del Estado. El resultado de esta elección es que ese principio se convierte en la base principal del sistema constitucional actual y el último pilar de la protección de los derechos civiles.

Cabe destacar que el principio de la dignidad de la persona humana no es sólo una elección ética y moral, sino una norma jurídica, un valor guía que dirige las posiciones jurídicosubjetivas que definen los derechos, garantías y deberes fundamentales. También sirve para resolver los conflictos existentes entre los derechos fundamentales, imponiendo restricción de unos o otros, de acuerdo con la posibilidad de protección, promoción o por el menoscabo a la persona humana (MYSZCZUK, 2005).

Es un elemento informante y básico de todos los derechos fundamentales, tiene una función integradora y hermenéutica como parámetro para la aplicación, interpretación e integración de las normas de derechos fundamentales. Como ya dicho, es la base para la imposición de restricciones a los derechos fundamentales, actuando tanto como límite de derechos como límite de los límites a las restricciones a los derechos fundamentales (MYSZCZUK. MEIRELLES: 2010).

Cabe comentar que en el ámbito de las Biotecnologías existe una profunda preocupación por la posibilidad de manipulación del genoma en su totalidad o integralidad y, por lo tanto, dañarse a la dignidad del ser humano. Romeo Casabona (1999) analiza las posibilidades de 
limitar la investigación científica y afirma que existen tres modelos jurídicos presentes en las distintas leyes nacionales e internacionales sobre el tema.

El primer considera que la obtención de conocimientos científicos no debe estar sujeta a ningún tipo de limitación, ya que, como tal, no es perjudicial ni beneficiosa, sino más bien su uso. El segundo determina que cualquier investigación dirigida a obtener conocimiento que pueda ser utilizado más adelante en detrimento del individuo o de la colectividad es contraria a la Ética, y puede estar prohibida. El tercer modelo establece que la adquisición de conocimientos, como tal, no debe limitarse, excepto las correspondientes a su uso o aplicación posterior.

Brasil adopta, de forma general, el tercer entendimiento. El límite de posibilidad de realizar un procedimiento es la defensa del ser humano como un valor en sí mismo, que debe respetarse incluso sin tener en cuenta, en su conjunto, los beneficios que se pueden obtener para terceros o para la colectividad. Asimismo, la existencia del desarrollo científico sólo se justifica si sirve para promover la existencia digna de la persona humana y para contribuir a mejorar la calidad de vida del ser humano y de la especie.

Impone la consideración de la persona como el único fin del Derecho, nunca como un medio para alcanzarse el conocimiento científico o la ganancia financiera. Entender la persona humana como un fin significa respetarla y tratarla como una alteridad y, por lo tanto, reconocerla como un ser diverso y un centro de dignidad único que es único y no puede ser reemplazado por otro 5 .

De todos los modos, la dignidad de la persona implica en una comprensión determinada, que presupone el reconocimiento de su cualidad como ser humano, por el simple fato de ser humano. No puede ser tratado con discriminación por sus características, ni utilizado como un instrumento (cosa) para lograrse propósitos ajenos al ser humano, no tan valiosos como estas situaciones (ROMEO CASABONA, 1994).

Por todo ello, el principio de dignidad humana es una condición indispensable para la existencia del Estado Democrático de Derecho, convirtiéndose en un criterio de legitimación del poder constituido y del orden constitucional. Desechó cualquier práctica científica que ponga en peligro la existencia de una vida digna de un ser humano, que haga imposible seguir existiendo con dignidad o que cause daños irreparables e irreversibles a su integridad física o psíquica.

\footnotetext{
${ }^{5}$ La dignidad de la persona humana está relacionada con la idea de la o otra cosa, que no presupone al otro como igual; por lo tanto, busca tratar la dignidad con la igualdad binomial y la reciprocidad, que sólo es apropiada si es de la idea de la diferencia
} 
Del mismo modo, no se permiten intervenciones que traten al ser humano como una cosa o un simple medio para obtener conocimientos científicos o ganancias económicas. En otras palabras, no permite tratar a la persona de una manera que dañe su salud, seguridad, bienestar o cree condiciones adversas para la continuidad de su existencia (MYSZCZUK. MEIRELLES: 2010).

Sin embargo, como recuerdan Padilha y Bertoncini (2016), definir jurídica y filosóficamente la dignidad de la persona humana no es una tarea fácil, y se puede afirmar que tratase de un concepto vacío, cuyo contenido depende de la cultura y del contexto histórico de cada grupo de seres humanos. En raras ocasiones utilízaselo como argumento definitivo, convirtiéndose en un argumento de autoridad, vacío y reacio al diálogo. Al mismo tiempo, esta categoría es utilizada cada vez más a menudo con una excesiva "manipulación" por juristas o moralistas, lo que puede conducir a un vaciado del contenido de valor de ese instituto (ROMEO CASABONA, 1994).

Luego, la dignidad humana sólo puede convertirse en un argumento apropiado cuando dejar de ser un concepto general, abstracto y cambiante y pasar a una definición materialmente concreta y positivada. Es decir, cuando se convertir en un marco jurídico preciso, concreto y racional para la intervención, utilizado únicamente cuando otros instrumentos, como los derechos fundamentales, no aporten las soluciones jurídicas necesarias al caso concreto. (ROMEO CASABONA, 1994).

Debido a esta singularidad, una interpretación bioconstitucional debe basarse en un concepto más amplio de dignidad y actuar concretamente en la promoción de existencia de la persona, con calidad y respeto. A partir de esas características y para definir materialmente cuál sería su complejo de derechos y deberes fundamentales, se propone el entendimiento de que, ante una hermenéutica bioconstitucionalizada, se considera humanamente digno sólo lo que cumple simultáneamente los criterios de: solidaridad, tolerancia y sostenibilidad.

Solidaridad con toda la humanidad, en sus generaciones presentes y futuras. La posibilidad de coexistencia entre la Ciencia y la sociedad depende de un cambio global (CARDOSO, 1998). Es necesario superar la perspectiva ética basada en el sujeto aislado y abstracto y adoptarse a una actitud basada en la responsabilidad universal y solidaria frente a los desafíos del siglo XXI (HERRERO, 1999).

En una hermenéutica bioconstitucionalizada, el criterio de solidaridad es un deber de toda la sociedad de ayudar a los débiles y a los desamparados. Debe ser adoptar y llevado a cabo en plena armonía con otros principios constitucionales, servir de justificación para los derechos fundamentales y estar en consonancia con los parámetros de ciudadanía, erradicación 
de las desigualdades y cooperación entre personas, pueblos y toda la humanidad mientras especie. También tiene el mérito de ser un instrumento de enriquecimiento y humanización del Derecho, aportando al entorno jurídico, valores que son nobles y esenciales para la vida en sociedad (ROSSO, 2007).

Tolerancia a lo diferente, respeto do la diversidad cultural, social, económica, política, de género, sexual, religiosa, etc. Uso de posiciones democráticas para liberar al ser humano de cualquier forma de opresión. Consecuentemente, es, sin duda, la superación del uso del conocimiento científico como una razón instrumental y la construcción de una responsabilidad de la razón. El sujeto abstracto del sistema jurídico clásico debe convertirse en un sujeto ético y moral, consciente de sí mismo y de los demás, dotado de voluntad racional, un ser que se reconoce a sí mismo como responsable y que puede determinarse a sí mismo (CARDOSO, 1998).

Desde la perspectiva de la dignidad de la persona humana, la Declaración de Principios sobre la Tolerancia (UNESCO, 1995) es un elemento central para la dirección jurídica. En esta regulación, se describe la tolerancia como "el respeto, la aceptación y la apreciación de la riqueza y diversidad de las culturas de nuestro mundo, nuestros modos de expresión y de formas de expresar nuestra calidad como seres humanos". Representa la armonía en la diferencia, un hito para reemplazar una cultura de guerra por una cultura de paz. Representa una actitud activa basada en el reconocimiento de los derechos universales de la persona humana y de las libertades fundamentales del otro.

La Declaración eleva la tolerancia a la categoría de apoyo a los derechos humanos, el pluralismo, la democracia y el Estado de Derecho. Implica que toda persona tiene la libre elección de sus convicciones y acepta que la otra persona disponga de la misma libertad, aceptando el hecho de que los seres humanos tienen derecho a vivir en paz y a ser como son. Significa que nadie debe imponer sus opiniones a los demás, siendo un método universal de convivencia civil, que utiliza la persuasión, más que la fuerza y la coerción, teniendo como base común la práctica de la confianza en la capacidad de los demás para entender el bien común.

Por lo tanto, en una hermenéutica bioconstitucional, veta cualquier forma de discriminación, sea otorgando un beneficio ilegítimo a la persona o grupo, tratándolos favorablemente en detrimento de otras personas o grupos en igualdad de condiciones, o; imponiendo obligaciones, carga, sanción o cualquier sacrificio a la persona o grupo, discriminándolas desfavorablemente frente a otras personas o grupos en las mismas condiciones. Impone el deber de tratarse al ser humano con equidad, no se pueden imponer distintas condiciones para el cuidado de las personas en igualdad de situaciones. 
La sostenibilidad - en sus aspectos jurídico, social, ambiental y económico-financiero para hacer frente a los problemas ecológicos que nos hicieron tener que repensar la calidad del desarrollo científico actual (CARDOSO, 1998). La humanidad debe asumir las consecuencias de su acción desbalanceada y sin direccionamiento ético. La adopción de principios de responsabilidad solidaria puede crear herramientas para que la humanidad pueda garantizar la capacidad de gobernar los efectos del poder que el conocimiento científico ha proporcionado (HERRERO, 1999).

La sostenibilidad, más que un concepto, tiene como objetivo buscar el equilibrio entre todas las partes ambientales, locales y de posibles recursos que los seres vivos necesiten para sobrevivir y equilibrar las desigualdades sociales y económicas. La producción, el consumo exacerbados e, incluso sin sentido para existir, no pueden más prevalecen por encima de la existencia y continuidad de la especie humana.

En una hermenéutica bioconstitucional, es forzoso establecer un equilibrio entre el desarrollo social, el crecimiento económico y el uso de los recursos naturales, requiriendo una planificación territorial que tenga en cuenta los límites de la sostenibilidad. Este principio sería entonces uno que determine la satisfacción de las necesidades de las generaciones actuales, sin comprometer la capacidad de las generaciones futuras para satisfacer sus propias necesidades. Esto prioriza prácticas que evitan, reducen, corrigen o eliminan la posibilidad de causarse cambios en la calidad del medio ambiente (MYSZCZUK). MEIRELLES: 2010).

Los principios de solidaridad, tolerancia y sostenibilidad dan dimensión material a la dignidad humana, uniendo el ser con el deber de ser y el poder de hacer. Sobre la base de estos criterios, se redefine el aspecto ético y se considera el ser humano, sus relaciones con la sociedad y la naturaleza de manera integral. Permitiese la interpretación de los hechos basada en una racionalidad dialoga, interdisciplinaria, pluralista y democrática.

\section{CONSIDERACIONES FINALES}

El objetivo central de este paper fue verificar los puntos de contacto y encontrar un camino en el que la Ciencia, la Ética y el Derecho puedan producir una sinergia y colaborar para el desarrollo de la Ciencia como medio de empoderamiento del ser humano. El trabajo demostró que no sólo existe una posibilidad de interacción, sino la necesidad de una sinergia entre la Ciencia, la Bioética y el Bioderecho y que las formas jurídicas clásicas no tienen en cuenta la solución de las preguntas planteadas por la Biotecnología en el siglo XXI. 
En esta sinergia, la humanidad puede experimentar una transformación cualitativa, emprendiendo un camino de madurez y sabiduría y no sólo de conocimiento técnico. Se presentan nuevos tiempos y son fundamentales las características innovadoras de la transdisciplinariedad, la complejidad y el pluralismo divididos entre Bioética y Bioderecho.

Del mismo modo, los conceptos de solidaridad, tolerancia y sostenibilidad pueden hacer que el concepto de dignidad humana sea materialmente alcanzable y no sólo el argumento de autoridad, vacío y abstracto de las interpretaciones jurídicas tradicionales. Desde esta sinergia, es posible darse un paso más hacia el desarrollo de la Ciencia siendo sinónimo del empoderamiento del ser humano: el establecimiento de un núcleo bioconstitucional vinculado a la Biotecnología y sus relaciones con el ser humano. Este núcleo será indispensable en la construcción de un estatuto jurídico del ciudadano bioético y no más de una "persona" o del "sujeto de derechos" (ROMEO CASABONA, 2017, p. 13).

Además, es esencial reinterpretar varias de las normas jurídicas positivadas, buscándose bases nuevas o reoxigenadas para la resolución de cuestiones jurídicas (MYSZCZUK, 2012). El objetivo de la intervención del Bioderecho es proteger y garantizar el respeto de la libertad de pensamiento, creación y producción científica, estableciendo un marco jurídico adecuado para las diversas necesidades, compatibilizando la agilidad y el dinamismo con la seguridad jurídica requerida por el tema.

Todo ello debe incluir la protección de la investigación científica, de los descubrimientos biotecnológicos y de las innovaciones, de modo que se facilite el acceso de la población a los beneficios obtenidos o generados por la Biotecnología y a la protección, prevención o, al menos, minimización de los riesgos para los seres humanos, el medio ambiente y la materia viva en general (ROMEO CASABONA, 2007).

Por último, la intervención del Bioderecho debe servir para garantizar la convivencia y la paz social, para resolver los conflictos y para proteger los valores individuales y colectivos más importantes para la sociedad, sean esos ya reconocidos que requieran identificación y merezcan protección biojurídica.

\section{REFERENCIAS}

BARACHO, J. A. de O. A identidade genética do Ser humano. Bioconstituição: Bioética e Direito. Revista de Direito Constitucional e Internacional, v 32. p. 98-109. 
BORBA, M. de N. Bioética e Direito: biodireito? Implicações epistemológicas da Bioética ao Direito. Dissertação de Mestrado, Programa de Pós-Graduação em Bioética do Centro Universitário São Camilo, 2010. 74 p.

CAMBI, E. O caráter universal do direito moderno e os desafios fundamentais impostos pelo biodireito. In: CONRADO, M. CORRÊA, E. A. de A.; GIACOIA, G. (Coords.). Biodireito e dignidade da pessoa humana: diálogo entre a Ciência e o Direito. Curitiba: Juruá, p. 21-48, 2007.

CARDOSO, C. M. Ciência e Ética: alguns aspectos. Revista Ciência \& Educação, v. 5, n. 1, 1998, p. 01-06.

CUNHA, P. M. da. Princípio da dignidade da pessoa humana ressignificado a partir do Direito Civil-Constitucional prospectivo. In: EHRHARDT JÚNIOR, Marcos; CORTIANO JUNIOR, Eroulths (Coords.). Transformações no Direito Privado nos 30 anos da Constituição: estudos em homenagem a Luiz Edson Fachin. Belo Horizonte: Fórum, 2019.

DECLARAÇÃO, DE PRINCÍPIOS SOBRE A. TOLERÂNCIA. Unesco. Biblioteca Virtual de Direitos Humanos da USP http://www. direitoshumanos. usp. br/index. php, 1995.

FERRER, J. J. La Bioética como quehacer filosófico. Acta Bioética, v. 15, n1, 2009. p. 35-41. GODIN, J. R. Bioética: origens e complexidade. Revista HCPA, n. 26, v 2, 2006. p. 86-92.

GONÇALVES, M. E. Ciência e Direito: de um paradigma a outro. Revista Crítica de Ciências Sociais, n. 31, 1991. p. 89-113.

HERRERO, J. Desafios Éticos do mundo contemporâneo. Síntese (Revista de Filosofia), v. 26, n. 84, 1998. p. 05-11.

LIEDK, M. S. A Bioética e o Biodireito enquanto sistemas autopoieticos. Revista Juris, n. 14, 2009. p. 105-117.

LOUREIRO, C. R. M. Introdução ao Biodireito. São Paulo: Saraiva, 2009. 222 p.

MEIRELLES, J. O ser e o ter na codificação civil brasileira: do sujeito virtual à clausura patrimonial. In: FACHIN, L. E. (Coordenador). Repensando fundamentos do Direito Civil Brasileiro Contemporâneo. Rio de Janeiro: Renovar, 1998.

MORI, M. A bioética: sua natureza e história. Humanidades, n. 9, 1994. p. 332-341.

MYSZCZUK, A. P. Genoma humano. Curitiba: Juruá Editora, 2006.

MYSZCZUK, A. P.; MEIRELLES, J. M. L. La protección del ser humano en la era posgenómica: el ser humano inmaterial. Revista de Derecho y Genoma Humano, número especial, 2014. p. 401-409.

Bioethics, biolaw,(bio) constitutional interpretation and biopatents under the light of Brazilian law. Revista de Derecho y Genoma Humano. Law and the Human Genome Review, n. 33, p. 65-91, 2010. 
. Ser humano-informação e sociedade pós-genômica: a crise da proteção jurídica do sujeito de direitos em face das biopatentes. Revista de Estudos Constitucionais, Hermenêutica e Teoria do Direito, v. 9, n. 1, p. 65-74, 2017.

OLIVEIRA, S. B. de. Da Bioética ao Biodireito: manipulação genética e dignidade humana. Curitiba: Juruá, 2008. 216 p.

PADILHA, Elisângela; BERTONCINI, Carla. A dignidade da pessoa humana na teoria dos direitos fundamentais de Robert Alexy: uma análise sobre o seu caráter absoluto ou relativo na ordem jurídico-constitucional. Revista Brasileira de Direito, v. 12, n. 2, 2016. p. 137-145.

PEGORARO, O. A. Historicidade da ciência e da ética. Revista Bioethikos, v 4, n 1, 2010. p. 10-18.

PORTAL FIOCRUZ. www.portal.fiocruz.br. Acesso em 15.07.2020.

POTTER, Van Ressenlaer. Bioética: ponte para o futuro. Stevens Point: Universidade de Wisconsin, 1971.

REQUIÃO, Maurício. Covid-19 e proteção de dados pessoais: o antes, o agora e o depois. 05.04.2020. Disponível em: https://www.conjur.com.br/2020-abr-05/direito-civil-atual-covid19-protecao-dados-pessoais-antes-agora-depois . Acesso em 07.07.2020.

ROMEO CASABONA, C. M. et al. El derecho y la bioética ante los límites de la vida humana. Madrid: Centro de Estudios Ramón Areces, 1994.

ROMEO CASABOnA, C. M. Do gene ao Direito: sobre as implicações jurídicas do conhecimento e intervenção no genoma humano. IBCCrim, 1999.

El Bioderecho y la Bioética, un largo camino en común. Revista Iberoamericana de Bioética, n. 3, 2017. p. 1-16.

O desenvolvimento do Direito diante das Biotecnologias. In: ROMEO CASABONA, C. M. FREIRE DE SÁ, M. de F. Desafios jurídicos da biotecnologia. Belo horizonte: Mandamentos, 2007. p. 29-61.

ROSSO, P. S. Solidariedade e direitos fundamentais na constituição brasileira de 1988. Revista Eletrônica do CEJUR, v. 1, n. 2, 2007.

SILVA, M. R. da. HAYASHI, C. R. M. HAYASHI, M. C. P. I. Análise bibliométrica e cientométrica: desafios para especialistas que atuam no campo. Revista de Ciência da Informação e Documentação, Ribeirão Preto, v. 2, n. 1, jan/jun. 2011. p. 100-119.

STAFFEN, M. R.; ZAMBAM, N. J. Direito ao desenvolvimento humano enquanto bem jurídico global. Revista de Direito Brasileira, v. 11, n. 5, p. 22-43, 2015.

Submissão em 09/10/2020 / Aceito em 18/11/2020 